\title{
Commentary: Giant pulmonary artery aneurysm: Who needs a heart? Can't we all just get a lung?
}

\author{
Jules Lin, MD
}

\footnotetext{
From the Section of Thoracic Surgery, Department of Surgery, University of Michigan Medical Center, Ann Arbor, Mich.

Disclosures: Author has nothing to disclose with regard to commercial support.

Received for publication Sept 23, 2019; revisions received Sept 23, 2019; accepted for publication Sept 23, 2019; available ahead of print Oct 23, 2019.

Address for reprints: Jules Lin, MD, Section of Thoracic Surgery, 1500 E. Medical Center Dr, 2120TC/5344, Ann Arbor, MI 48109-5344 (E-mail: juleslin@umich.edu).

J Thorac Cardiovasc Surg 2020;159:2551-2

$0022-5223 / \$ 36.00$

Copyright (c) 2019 by The American Association for Thoracic Surgery

https://doi.org/10.1016/j.jtcvs.2019.09.095
}

In this issue of the Journal, Schwarz and colleagues ${ }^{1}$ report the largest published series of 7 patients with giant pulmonary artery aneurysms undergoing lung transplant. Although many centers consider these patients for heartlung transplant, the authors' approach is a bilateral lung transplant alone, using the donor pulmonary arterial trunk for reconstruction. Addressing this rare but complex problem requires careful preoperative planning and intraoperative techniques for successful reconstruction.

The prognosis of patients with pulmonary hypertension has improved and the timing of transplant delayed due to the effectiveness of new medications. However, with pulmonary artery aneurysms, increase in size is independent of normalized pressures, and progression of dilation and chest pain are indications for urgent transplant due to the risk of dissection and rupture. Large aneurysms can compress adjacent structures, and if left coronary stenting is required, drug-eluting stents and prolonged antiplatelet therapy should be avoided. Rightward shift of the airway can also make double lumen intubation more difficult. Acute increases in pulmonary pressures can lead to rupture or dissection, and hypercapnia should be avoided. Due to the risk of acute right and left ventricular failure, the surgery team should be in the room in case emergent cannulation for bypass is needed.

Although reconstruction using the donor pulmonary trunk was successful in all 7 patients, the length of the pulmonary trunk is not always adequate due to displacement by the large aneurysm. Force and colleagues ${ }^{2}$ and Oda and colleagues ${ }^{3}$ used the donor aorta for reconstruction. Other techniques include aneurysmorrhaphy or using vascular grafts and homografts. ${ }^{4,5}$ For large size mismatches, a pericardial patch may be needed. ${ }^{3}$ Oda and colleagues ${ }^{3}$ describe using a 3-dimensional printed model, which could be useful to visualize structures preoperatively. Intraoperative transesophageal echocardiogram is important to determine the degree of pulmonary insufficiency from a dilated valve annulus stenotic valve.

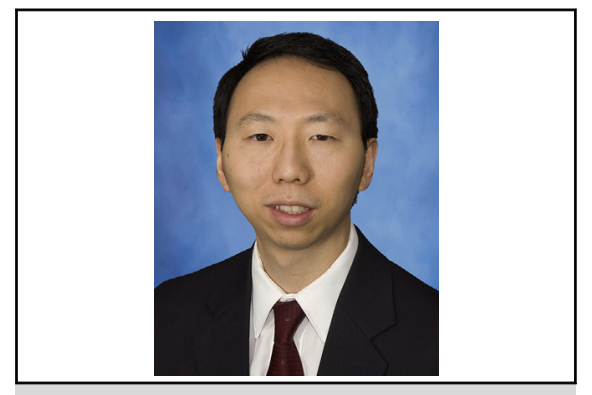

Jules Lin, MD, FACS, FCCP

Central Message

Giant pulmonary artery aneurysms are a rare but complex problem requiring careful preoperative planning and intraoperative techniques for successful reconstruction with lung transplant alone.

See Article page 2543.

before and after reconstruction. Although Schwarz and colleagues found the pulmonary valve to be competent in all 7 patients, Shayan and colleagues ${ }^{6}$ performed a commissuroplasty for moderate pulmonary insufficiency and Zanotti and colleagues ${ }^{7}$ harvested the donor right ventricular outflow tract en bloc to replace a congenitally

Although Schwarz and colleagues found no difference in cold ischemia times, delaying reperfusion of the right lung while implanting the left pulmonary artery into the pulmonary trunk would prolong the warm ischemia time for the right lung. Reconstructing the left main pulmonary artery 2 to $3 \mathrm{~cm}$ from the bifurcation so cardiac function and right pulmonary artery perfusion can be resumed could shorten the aortic crossclamp and warm ischemia times. Force and colleagues ${ }^{4}$ released the left atrial clamp while controlling the pulmonary artery with bulldog clamps, allowing some retrograde perfusion during the pulmonary arterial reconstruction. Zanotti and colleagues ${ }^{7}$ and Shayan and colleagues ${ }^{6}$ performed the pulmonary arterial reconstruction without cardiac arrest.

Giant pulmonary artery aneurysms in patients undergoing lung transplant remain challenging. Although many centers consider these patients for heart-lung transplant, Schwarz and colleagues provide additional evidence that successful reconstruction may not require a heart, as long as we can all just get a lung. 


\section{References}

1. Schwarz S, Benazzo A, Prosch H, Jaksch P, Klepetko W, Hoetzenecker K, Vienna Lung Transplant Group. Lung transplantation for pulmonary hypertension with giant pulmonary artery aneurysm. J Thorac Cardiovasc Surg. 2020;159:2543-50. 2. Force SD, Lau CL, Moazami N, Trulock EP, Patterson GA. Bilateral lung transplantation and pulmonary artery reconstruction in a patient with chronic obstructive pulmonary disease and a giant pulmonary artery aneurysm. J Thorac Cardiovasc Surg. 2003;126:864-6.

3. Oda H, Hamaji M, Motoyama H, Ikeda T, Minatoya K, Nakajima D, et al. Use of a three-dimensional model in lung transplantation for a patient with giant pulmonary aneurysm. Ann Thorac Surg. August 22, 2019 [Epub ahead of print].
4. Kuwaki K, Morishita K, Komatsu K, Abe T. Graft replacement for huge aneurysm of the main pulmonary artery. Ann Thorac Surg. 2000;70:1714-6.

5. Iosifescu AG, Dorobantu LF, Anca TM, Iliescu VA. Surgical treatment of a pulmonary artery aneurysm due to a regurgitant quadricuspid pulmonary valve. Interact Cardiovasc Thorac Surg. 2012;14:880-2.

6. Shayan H, Sareyyupoglu B, Shigemura N, Thacker J, Bermudez C, Toyoda Y. Lung transplant, double valve repair, and pulmonary artery aneurysm resection. Ann Thorac Surg. 2012;93:e3-5.

7. Zanotti G, Hartwig MG, Duane Davis R. A simplified technique for pulmonary artery aneurysm repair in a lung transplant recipient with right ventricular outflow tract obstruction. J Thorac Cardiovasc Surg. 2013;145:295-6. 